are already aware of all these many difficulties and are ready to accept the convenience of the concept of 'fitness' in evolutionary theory, when faced with the necessity to explain.

Finally, I think that it is only right to point out that man refuses to conform to many of the generalizations which have arisen in comparative study. All would agree that Adrian Spigelius of Padua in the I6th century did a great disservice to science when he insisted on the formal separation of study of the anatomy of man from comparative studies of anatomy as a whole. I do not wish to be accused of the same attitude of mind when I say that man is a very curious mammal! No doubt Dr Cuthbertson in the last paper this afternoon will put man in his correct perspective relative to other mammals.

\title{
Comparative nutrition, growth and longevity
}

\section{By Elizabeth Evans and D. S. Miller, Queen Elizabeth College, London, W8}

Needham (194I) has said that there are two sorts of people-those that like generalizations and those that abhor them. In discussing species of living organisms we fall into the first category though we are aware of specific differences. Biochemically the cells of a whale are very similar to those of an amoeba, in as much as both have nuclei and cytoplasm, and comparable metabolisms of energy and nitrogen. Both contain simple sugars and complex proteins and would not function without these. All animals can utilize simple sugars, and some can utilize also more complex substances such as fats and cellulose as energy sources. Their requirement for nitrogen shows more variation: some can utilize simple sources of nitrogen while others require specific amino acids. The field of study of the nutritionist has been generally limited to birds and mammals. The distinctive feature of the two groups is that they have developed homoeothermic mechanisms, and as a result, are less dependent on the environment. The number of species whose nutritional requirements are known with any precision is relatively few. Of the mammals only about a dozen species have been studied out of a total of over 5000 : the situation with birds is worse.

\section{Food intake}

Zoologists have described animals according to the diets they consume: carnivores, insectivores, omnivores and herbivores and this has much to commend it in studying the ways in which animals have adapted to their food. Unfortunately taxonomists have chosen to use Carnivora and Insectivora as the names of classes whose members are not entirely flesh-eating or insect-eating which is sometimes confusing.

Modifications associated with the diet are shown by differences in the dentition, digestive system and body conformation. Carnivorous mammals and birds typically have strong jaws and necks, sharp claws which help in the prehension of food and 
large stomachs; they need only short guts for digestion. The birds have strong, sharp beaks, and the mammals have a heterodont dentition with marked canine teeth. Fish-eating carnivores have streamlined bodies adapted to fish catching; and similarly, anteaters are adapted to ant catching. Herbivores, on the other hand, use lips and tongues for the prehension of food; they have developed incisor teeth for cutting plants, and plate-like molars for grinding leaves to release cell contents. The gut is typically complex and harbours micro-organisms which produce cellulases: this is facilitated in ruminants by a system of four stomachs, and in other species by an enlarged caecum or colon or both. As with the carnivores, some species are adapted anatomically to specialized food supplies, for example, giraffes, elephants and tapirs. Such animals have evolved to fill ecological niches, but we have no data to suggest that they have metabolic adaptations different from other carnivores and herbivores.

In our own studies with zoo animals, we have classified diets according to the percentage of calories derived either from flesh (including fish and insects) or from herbage (hays and pasture crops). The food intakes have been computed from weighed dietary measurements of up to six individuals of each species. We must stress that our values refer to the free choice of foods of animals kept in captivity where there was no public feeding. Whereas every effort is made in the zoo to make available a selection of liberal quantities of foods known to be consumed in the wild, the environment is, of course, highly artificial. However, one must distinguish between wild animals kept in captivity, and domesticated animals kept for commercial reasons. In the latter, food habits and performance are standardized and are very different to those of wild animals, even those in captivity. We know a lot about the nutrition of domestic animals and virtually nothing about animals in the wild. Our findings refer to animals maintained in between these two extremes, which have a good expectation of life and a reasonable reproductive performance, standards usually accepted for dietary adequacy.

Arbitrarily, we have defined carnivores as animals taking more than half their calories from flesh, herbivores as taking more than half their calories from herbage, and omnivores as animals obtaining their calories from mixed sources. However, the classification of animals by anatomical characteristics does not consistently indicate feeding habits, and Fig. $1 a$ shows that far from all the Carnivora are carnivorous. Thus the kinkajou (Potos flavus) and the spectacled bear (Tremarctos ornatus) hardly consume any of the animal foods offered them, and the giant panda (Ailuropoda melanoleuca) which has a typical carnivorous gut is reputed to live solely on bamboo shoots in the wild, although in the zoo it also receives rice, milk and eggs. Although the majority of the species within the class take more than half their calories as meat, an example can be chosen at almost any level between $100 \%$ for cats and $2 \%$ for the kinkajou.

Similarly not all the Ungulata, typical herbivores, eat predominantly herbage. There is a wide variation in the intake of herbage of these animals, and at least two species, the bush pig (Potamochoerus porcus) and the wild boar (Sus scrofa) avoid it altogether. Of the twenty-eight species of Ungulata examined, eleven would be 


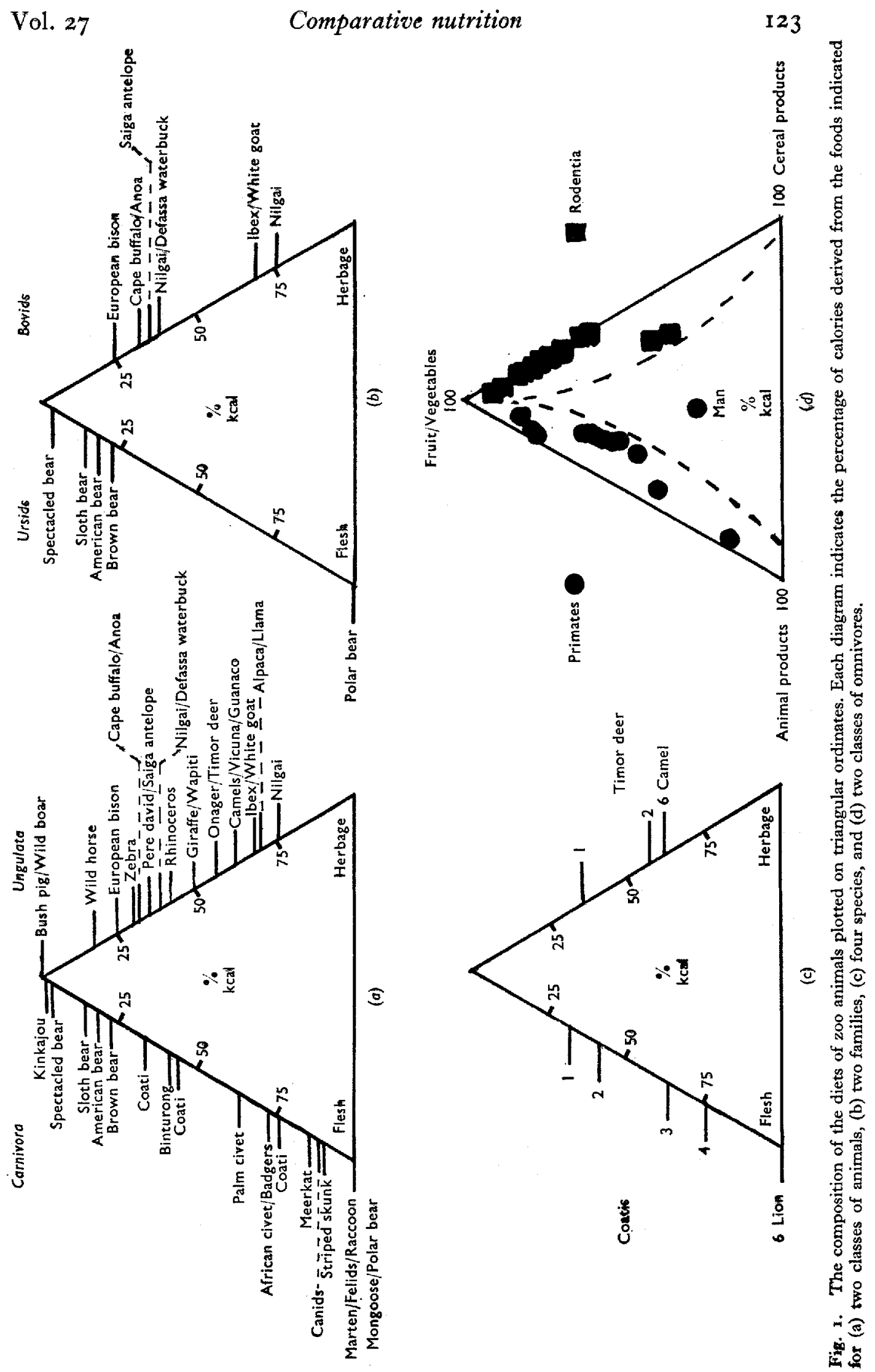


classified as omnivorous. We find the same wide variation also within families (Fig. I $b$ ). Thus although the bears are predominantly omnivorous Carnivora, there is one species that is exclusively carnivorous. Similar variations are shown even between individuals of the same species (Fig. Ic); we find flesh preferences of individual coatis (Nasua nasua) ranging from $34-76 \%$ of their calorie intake, although the six lions examined took their calories exclusively as meat. In Fig. id an attempt has been made to classify the diets of two typical classes of omnivores, Primata and Rodentia, by considering calories derived from cereals, animal products, and fruit and vegetables. It will be seen that the two classes of mammals occupy different areas of the graph: thus both classes ate fruit and vegetables, but the primates ate more animal products and the rodents more cereals. The human diet (UK) falls more centrally and indicates that man is the most opportunist omnivore.

\section{Nutrient intakes}

Comparative studies of the calorie requirements of different species began as long ago as 1839 when Sarrus and Rammeaux proposed their theory that the rate of heat production of animals was proportional to their surface area. The theory has had many adherents including Rubner and Voit, the famous physiologists of the last century, but this apparently reasonable proposition does not take into account that heat loss is controlled by homoeostatic mechanisms: also there is a wide range of values for the insulation of the bodies of different species (e.g. wolf 8 'clo units', shrew I 'clo unit', I 'clo unit' being the amount of insulation provided by the clothing a man usually wears at room temperature (Irving, 1966)). It is now known that metabolic rate is more closely related to a power of body-weight (Brody \& Procter, 1932) and, since it is convenient to relate many nutritional parameters to this function, Kleiber (1947) has defined the 0.75 power of body-weight in $\mathrm{kg}\left(W^{0.75}\right)$ as metabolic body size. Thus the basal metabolic rate of mature animals of species ranging from mouse to elephant is equal to $70 W^{0.75} \mathrm{kcal} / \mathrm{day}$, and their endogenous nitrogen excretion to $146 W^{0.75} \mathrm{mg} \mathrm{N} /$ day. These values have been used to calculate the calorie and protein requirements of different species including man (FAO, 1957; 1965). In our own studies we have also expressed nutrient intakes per unit of metabolic body size.

In Fig. $2 a$ are shown the voluntary calorie intakes of 120 species of zoo animals grouped in families, together with their predicted basal metabolic rates. The intakes are in terms of metabolizable energy taken from appropriate food tables. It will be seen that the calorie intakes $\left(146 W^{0.75} \mathrm{kcal} /\right.$ day) are almost exactly twice that required for basal metabolism, in close agreement with the maintenance requirements proposed by Brody (1945). The one exception is the polar bear (Thalarctos maritimus) which took $400 W^{0.75} \mathrm{kcal} / \mathrm{day}$. This was achieved by taking 40000 kcal daily in about $4 \mathrm{~h}$, and may be related to its arctic origins. The efficiency with which the metabolizable energy is used could well vary between species: Mitchell (i964) has collected data for five species of farm animals and shows that the net availability of the metabolizable energy of starch ranges from $57 \%$ for hens to $83 \%$ for pigs. If we assume that diets contain on average $4 \mathrm{kcal} / \mathrm{g}$ dry weight and are 

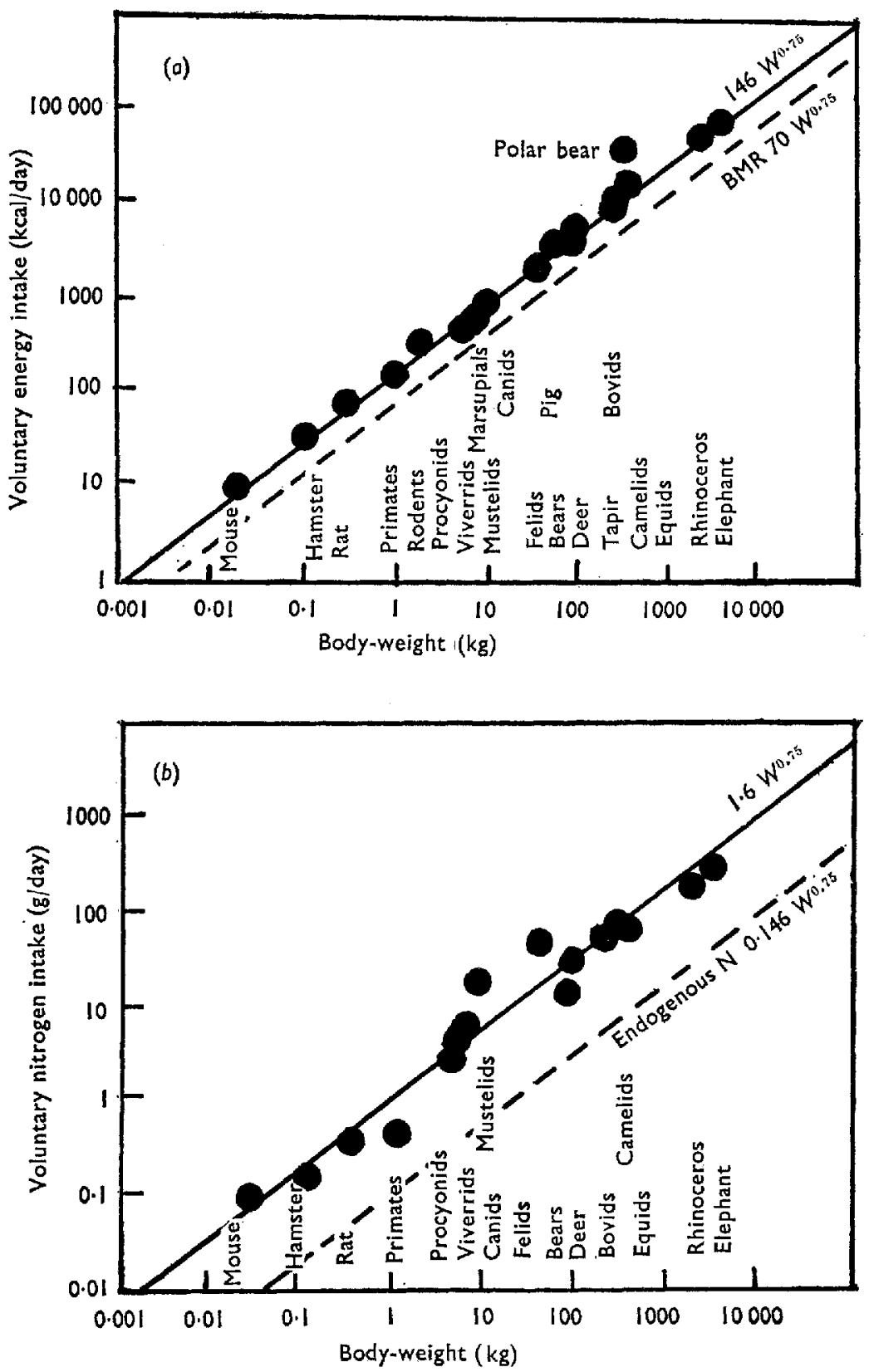

Fig. 2. Relationship between voluntary food intake and body-weight. The broken lines indicate (a) predicted basal metabolic rate, and (b) predicted endogenous nitrogen excretion.

$15 \%$ dry weight, then from the regression equation it is possible to calculate which animals could eat their own weight of food (for $146 W^{0.75} \times \frac{100}{15} \times \frac{1}{4} \ngtr 1000 \mathrm{~W}$; then 
$W \ngtr 3.2 \mathrm{~g}$ ). Thus it is just possible for shrews to achieve the feat traditionally attributed to them, and they cannot be regarded as exceptional eaters (Hawkins \& Jewell, 1962).

The voluntary protein intakes in Fig. $2 b$ show much more variation; although the correlation coefficient is statistically significant, the physiological significance is open to doubt because of the enormous range. Endogenous nitrogen excretion for different species is remarkably constant $\left(146 \mathrm{mg} / W^{0.75}\right.$ ) and it seems reasonable to assume that minimum protein requirements are also constant. However, the carnivores, particularly the canids and felids, derive much of their calories from protein, whereas other species, for example the primates, utilize their dietary protein primarily to balance inevitable nitrogen losses. This dual function of protein explains the variations of nitrogen intake and does not invalidate the calculations of Miller \& Payne (1964) who give the minimum maintenance requirements as $250 W^{0.75} \mathrm{mg} \mathrm{N} /$ day, a figure shown to apply to a number of species including man. The difficulty of converting this figure into dietary protein requirements is lack of quantitative knowledge of specific essential amino acid requirements; where known, these are basically the same for domesticated non-ruminant animals, but ruminants by virtue of their gut flora can be fed entirely from inorganic nitrogen sources (Virtanen, 1966). Where similar diets have been fed to a number of non-ruminant species, the values for net protein utilization (NPU) have been similar: for example the NPU (standardized according to the method of Miller, r963) of casein is 70 in the rat (Kon, I928), 69 in the dog (Allison, 1955), 68 in man (Hawley, Murlin, Nasset \& Szymanski, 1948), and 80 in the calf (Blaxter \& Wood, 1952). However, the NPU of blood for the rat is zero (Miller \& Bender, 1955), but is obviously higher in the vampire bat (Desmodus rotundus) which uses blood as its sole protein source.

\section{Growth}

Young animals require nutrients for growth as well as for maintenance, and it is possible to calculate requirements from their growth rates. According to the classical work of Brody (1945) these may be divided into two phases, self-accelerating $\left(W=A^{*} e^{k^{* t} t}\right)$ and self-inhibiting ( $W=A-A e^{-k\left(t-t^{*}\right)}$, where $W=$ weight, $t=$ time, $t^{*}$ is a correction to allow for gestation, $A^{*}$ is weight at conception, $A$ is mature weight, $e=2 \cdot 72$, and $k, k^{*}$ are growth constants), which together yield a composite sigmoid curve. The constants in Brody's equations are empirically derived and do not include nutritional factors, such as protein and calorie intake, although this has been attempted by others (Miller \& Payne, 1963; P. R. Payne \& E. F. Wheeler, 1967, personal communication). Growth curves from different species including populations of micro-organisms may be superimposed if the age ordinate is adjusted between conception and mature weight (Brody gives an excellent graphical method for solving the constants in the equations). The human growth curve differs from the others in having a very long juvenile period between weaning and puberty, and this may have significance in capacity to learn. Certainly it has a big influence on nutrient requirements at this time; for instance, the needs of a baby pig weighing the same as a human baby must be far greater if it is to achieve the weight of a man 
in 6 months. Recent data for other primates (L. G. Smith, r968, personal communication) fall intermediary between that for man and the non-primates: thus the gorilla, orang utan, chimpanzee and even the rhesus monkey also have extended juvenile periods though not as extensive as in man. In Fig. 3 we have included new results for the polar bear and the African elephant, and these are identical with the curve previously established for laboratory and domestic animals.
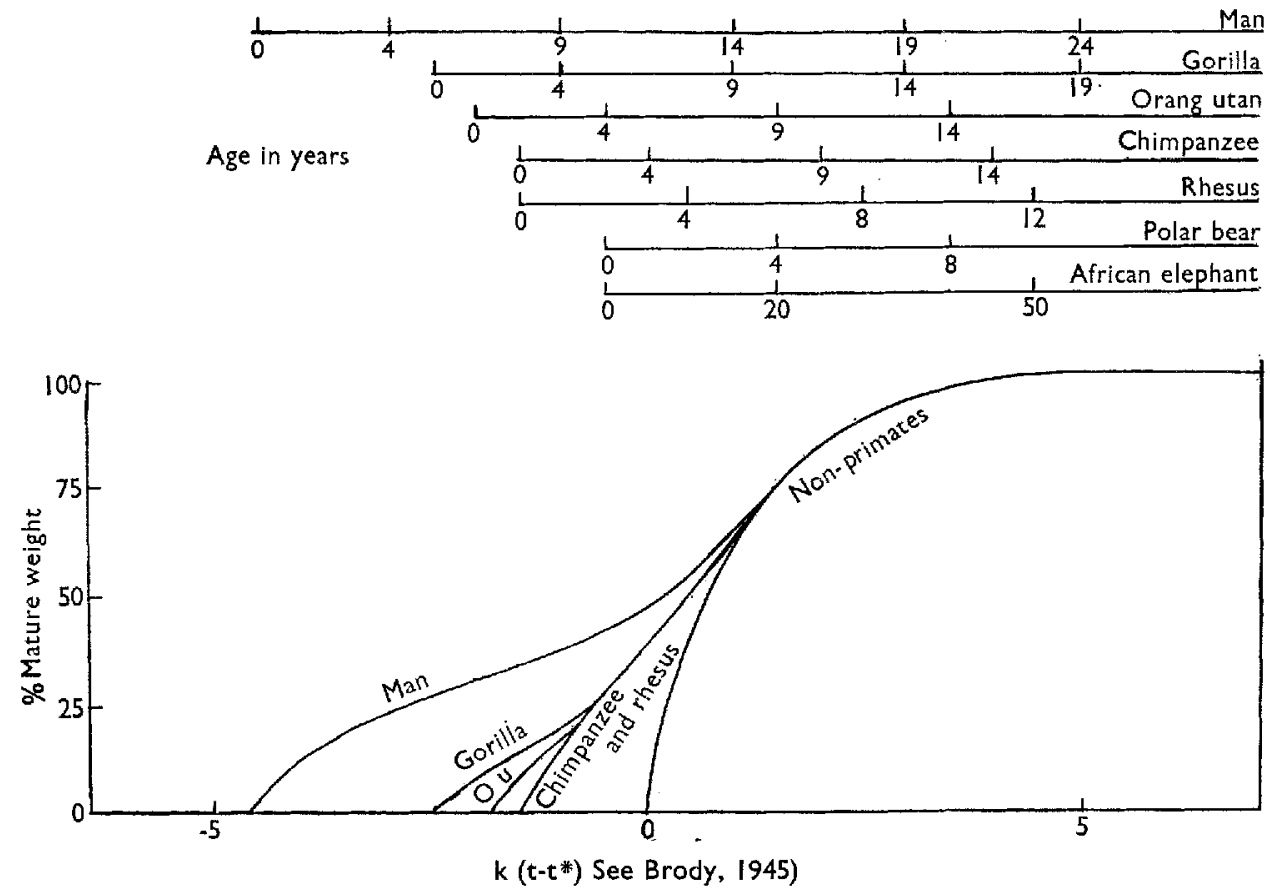

Fig. 3. Growth curves of different primates in relation to those established for non-primates (Brody, I945).

\section{Longevity}

The life span of animals is determined by a complex set of social, environmental, nutritional and other biological factors. Longevity in mammals is roughly correlated to weight, relative brain size and reproductive performance (Comfort, 196I). Thus the maximum life span of a 3 -ton elephant is about 70 years, whilst that of a $10 \mathrm{~g}$ shrew is less than 2 years: man, who has a relatively large brain in relation to bodyweight, lives to 70 years, whereas a pig of the same weight lives only 20 years; and the slow-breeding bats have longer life spans ( 15 years) than fecund rats or mice (5 years). The potential life span in birds is usually much longer than that of similar sized mammals; for example, the eagle owl has been recorded to live 68 years, and many small captive birds attain 20 years. The life span of cold-blooded animals is longer than that of warm-blooded animals; tortoises are reliably recorded to live to 150 years, and ages of up to roo years have been claimed for sturgeon. Among 
the invertebrates the longest living are probably the large bivalve molluscs at roo years. These and other factors are reviewed more fully elsewhere (Ciba, 1959) and we have concentrated on comparative and nutritional aspects.

Minot (I889) pointed out that, since growth rate declines with age, senescence is essentially retardation of growth. This led Brody (1945) to plot his growth constant ( $\mathrm{k}$ in the equation for self-inhibiting growth, sce $\mathrm{p}$. 126 ) against duration of life, and showed that the longer the growth period the longer the life span. Thus one would expect the primates shown in Fig. 3 to live longer and this is in agreement with Flower (193I): man is, of course, the longest-living primate. Rubner (1908) was the first to propose a more nutritional theory of longevity when he calculated that the energy metabolized per unit body-weight for a lifetime was approximately the same for all warm-blooded animals, the value being about $200 \mathrm{Mcal} / \mathrm{kg}$ except for man at $800 \mathrm{Mcal} / \mathrm{kg}$ and this may be associated with his longer growing period. More recently Bourlière (1957) reviewed vertebrate and invertebrate evidence for a correlation between longevity and energy turnover, which may be influenced by environmental temperature, especially in cold-blooded animals, and by food intake. He suggests that the common denominator for both factors is metabolic rate.

In mammals, McCay, Crowell \& Maynard (I935) showed that rats on severely calorie-restricted but otherwise complete diets lived longer than animals fed ad lib., and Berg \& Sims (I96I) showed that a more moderate restriction of food intake throughout life also increased life expectancy. However, those who have repeated these experiments will have observed the miserable state of the long-living rats, and such an approach is not a practical solution to extending life span. Miller \& Payne (1968) show that by feeding rats diets designed to meet the varying requirements of the rats throughout life, they could not only improve life expectancy but also maintain the rats in good condition: these rats had an extended mature life in contrast to those of McCay which had an extended juvenile period. Sinclair (I95 r) expressed concern at the increased growth rate of children which could lead to a shortening of life span, but the more recent work suggests that a frugal diet in maturity might be a more satisfactory way of extending life. Man is the longest-living mammal, but we still do not know if this is due to his weight, his relative brain size, his slow growth rate or his diet; certainly individuals can lower this high expectancy by $13 \%$ for every $10 \%$ they are overweight.

\section{Conclusion}

In conclusion, many species of animals derive their nutrients in a variety of ways but fundamental requirements are very similar. Thus if one were faced with a completely new species in the zoo, one could prescribe with some degree of certainty calories and protein; an examination of the animals might indicate the type of food to which they were adapted but the menu would still be a matter of trial and error. With a young animal one could state the shape of its growth curve, and predict its growth rate knowing the voluntary food intake. One might even hazard a guess at its expectancy of life. The accuracy of these predictions would not satisfy the experimentalist concerned with individual animals, but it is remarkable that they show 
any agreement at all with reality in view of the wide range of species to which they apply: we hope that they may contribute to a better understanding of some nutritional principles.

We should like to thank Professor Yudkin for his encouragement and advice and ICI for a Research Grant.

\section{REFERENCES}

Allison, J. B. (1955). Physiol. Rev. 35, 664.

Berg, B. N. \& Sims, H. S. (196r). F. Nutr. 74, 23.

Blaxter, K. L. \& Wood, W. A. (1952). Br. $\mathscr{F . ~ N u t r . ~ 6 , ~} 56$.

Bourlière, F. (I957). The Biology of Ageing. Symposia of the Institute of Biology 6, 27.

Brody, S. (r945). Bioenergetics and Growth. New York: Hafner Publishing Co. Inc.

Brody, S. \& Procter, R. C. (1932). Res. Bull. Mo. agric. Exp. Stn no. I 6 .

Ciba (1959). Ciba Fdn Colloq. Ageing. Vol. 5.

Comfort, A. (196r). Scient. Am. 205, no. 2, p. 108.

FAO (1957). F.A.O. nutr. Stud. no. 16.

FAO (1965). F.A.O. nutr. Stud. no. 301.

Flower, S. (1931). Proc. zool. Soc. Lond. p. I45.

Hawkins, A. E. \& Jewell, P. A. (r962). Proc. zool. Soc. Lond. 138, I37.

Hawley, E. E., Murlin, J. R., Nasset, E. S. \& Szymanski, T. A. (1948). F. Nutr. 36, I53.

Irving, L. (I966). Scient. Am. 2 14, no. 1, p. 94.

Kleiber, M. (1947). Physiol. Rev. 27, 5 I I.

Kon, S. K. (1928). Biochem. F. 22, 261.

McCay, C. M., Crowell, M. F. \& Maynard, L. A. (1935). F. Nutr. ro, 63 .

Miller, D. S. (1963). Publs natn. Res. Coun., Wash. no. I100, p. 34.

Miller, D. S. \& Bender, A. E. (т955). Br. F. Nutr. 9, 382.

Miller, D. S. \& Payne, P. R. (1963). F. theor. Biol. 5, 1398 .

Miller, D. S. \& Payne, P. R. (1964). Proc. Nutr. Soc. 23, I1.

Miller, D. S. \& Payne, P. R. (I 688 ). F. exp. Geront. 3, 23 I.

Minot, C. S. (1889). F. Physiol., Lond. 12, 97.

Mitchell, H. H. (1964). Comparative Nutrition of Man and Domestic Animals. Vol. 2. New York: Academic Press, Inc.

Needham, J. (I94I). Time the Refreshing River. London: Allen \& Unwin.

Rubner, M. (1908). Das Problem der Lebensdauer und seine Beziehungen zu Wachstum und Ernährung. Munchen and Berlin. Oldenburg.

Sarrus \& Rammeaux (1839). Bull. Acad. r. Méd. belg. 3, I094.

Sinclair, H. M. (1951). New Fngl. F. Med. 245, 39.

Virtanen, A. I. (1966). Science, N.Y. 153, 1603.

\section{Comparative nutrition in pregnancy and lactation}

\section{By P. R. Payne and Erica F. Wheeler, Department of Human Nutrition, London School of Hygiene and Tropical Medicine, Keppel Street, London, $W C_{\mathrm{I}}$}

A comparative study of any aspect of the nutrition of mammals must be based upon recognition of the fundamental similarities which exist within the group. We assume that each animal will have certain measurable characteristics, which vary between members of the group, but which are related according to a basic pattern. 